\title{
Angiology
}

The Journal of Vascular Diseases

\section{The Socioeconomic Profile of Patients Treated by Phlebotropic Drugs in Germany}

\author{
Andrea Uber, MBA
}

HANOVER, GERMANY

\section{A B S T R AC T}

Conservative treatment of venous disease is difficult. There is much skepticism concerning the efficacy of drugs in venous diseases. Nevertheless, in Germany, these drugs have obtained a substantial market share with a tendency to increase. The objective of this empirical study is to evaluate the socioeconomic characteristics of consumers of venous medications and to explore the demand elasticity with respect to health insurance coverage.

In a first set of inquiries 12,500 households were asked from July to September 1993 if they had purchased prescribed venous medication during the past 12 months. About 10,000 households with 19,750 persons aged fifteen years and older responded; $2,080(11 \%)$ of those persons had consumed prescribed medications against venous disease over the past twelve months.

In the second part of the study a detailed questionnaire was sent to the 2,080 purchasers and to 3,000 randomly selected nonpurchasers; $1,930(92.8 \%)$ purchasers and 2,291 (76.4\%) nonpurchasers returned their questionnaire. The key findings can be summarized as follows: The percentage of women is much higher in the group of purchasers $(80 \%)$ than in the group of nonpurchasers. Most of the purchasers are over fifty years old. Only one quarter of the purchasers are under fifty. One third of the purchasers are retired, and only $29 \%$ are working. In the group of nonpurchasers $56 \%$

(continued on next page)

From the Institute for Insurance Economics and North German Center for Health Services Research, University of Hanover, Germany

(C) 1997 Westminster Publications, Inc., 708 Glen Cove Avenue, Glen Head, NY 11545, U.S.A. 
(Abstract continued)

are working and only $17 \%$ are retired. A comparison of the distribution of purchasers and nonpurchasers over income classes and education levels shows that higher income and higher education are less prevalent in the group of consumers of venous medications. Varicose veins (58\%) and various leg complications $(30 \%)$ and pain in the legs $(30 \%)$ play a dominant role for applying venous medications. The analysis shows that pregnancy and chronic diseases are risk factors for venous diseases and are more prevalent in the purchasers group. We did not, however, discover a significant difference in the share of smokers, and it is quite low in the group of purchasers (14\%). Only $45 \%$ of the purchasers feel that their venous disease has a negative influence on their sparetime activities, their family life, or their work. Purchasers consult a physician on the average 3.7 times a year; $40 \%$ of the managers, merchants, and self-employed craftsmen have no physician consultation at all.

Owing to the pain and trouble of some complications of venous disease, only a relatively low percentage of purchasers would react to a reduction of health insurance coverage of venous medications; $5 \%$ would stop buying these drugs and $22 \%$ would reduce consumption if they would have to pay the cost out-of-pocket.

\section{Introduction \\ $\therefore$}

It is most often the limbs that are affected by venous diseases. Visible varicosity with valvular insufficiency, embolism, signs of local inflammation, node formation, skin discoloration, and peripheral dilatations through to the ulcus cruris characterize this disease. The primary objective of any treatment of these diseases is to improve the blood circulation in the diseased vessels and to eliminate blockages, swellings, and trophic skin damage.

Therapy comes in many forms. In symptomatic terms, the problems can be alleviated by pressure (bandages) or individually adapted support stockings, with simultaneous raising of the legs. Movement therapy, or prevention of prolonged immobilization, is extremely important in treating superficial venous diseases, for otherwise, thromboses can form. Operative measures promise the greatest success.

There is, however, scepticism toward medical therapy since the assessment of the therapeutic effectiveness of venous drugs is still disputed. Reserved or dismissive statements are countered by positive opinions. ${ }^{1}$ In many cases, however, a supportive role is attributed to the vascular agents available. ${ }^{2}$

\section{Methodological Procedure and Empirical Analysis of the Study}

In France this study was carried out in 1991 for the first time. ${ }^{3}$ The primary objective was to learn the characteristics of the group of patients or, in other words, the group of purchasers. By using a control group, in this case a group of nonpurchasers, it was possible to check whether the characteristics found were disease-specific. Second, the purchasing behavior of the consumers was to be assessed in the case of no reimbursement for phlebotonic medicines by the social security system.

To compare the results obtained in France, a similar study was carried out in two other European countries - Germany (not including the former East Germany) and Spain. The screening procedure was identical in the three European countries. It will be explained in greater detail with the example of Germany (Figure 1).

The study questionnaire can be divided into two phases. In the first phase, the selection phase, 12,500 households were contacted. The household members were divided into purchaser and nonpurchaser groups on the basis of their answer to the following question:

"Have you, or another member of your household, obtained one or more of the following pre- 


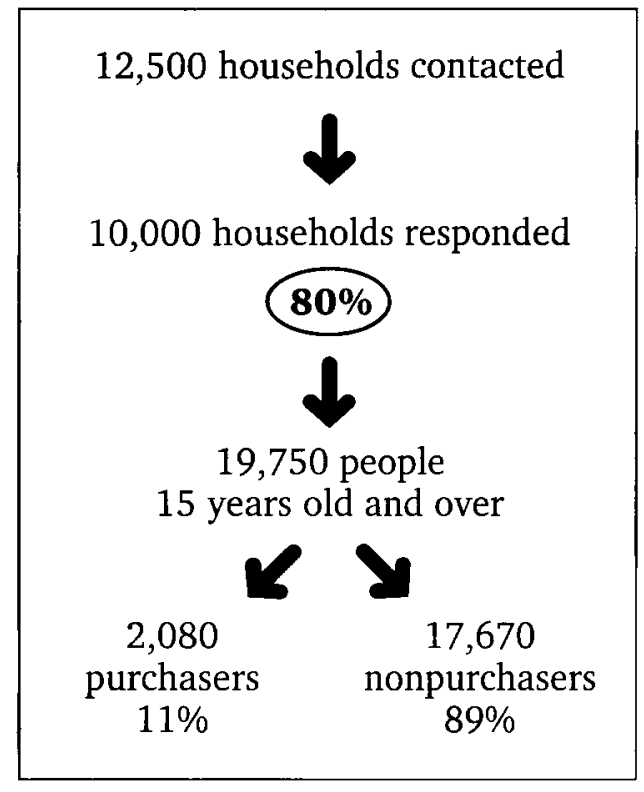

Figure 1. Results of the screening in Germany.

scription medicines, to relieve vascular problems in the legs, from the pharmacist within the last twelve months?"

The screening result of the first phase was a response from 10,000 households, ie, 19,750 household members, aged fifteen years and over, of the 12,500 households contacted. Of the 19,750 answers $2,080(11 \%)$ were in the purchaser target group, and $17,670(89 \%)$ in the nonpurchaser group.

The actual study begins with the second phase. To carry out this second phase, letters were written to all 2,080 purchasers and to 3,000 randomly selected nonpurchasers. These 5,080 people were sent a detailed questionnaire that was finally answered by 1,930 purchasers and 2,291 nonpurchasers.

The questions for the target group of purchasers can be divided into five categories:

1. Characterization of venous insufficiency (symptoms, severity of disease, methods of treatment, etc) (In this first category we look closely at the question of whether the purchaser would buy medicines, creams, or gels for leg complaints, even without a prescription.)
2. General state of health (hospitalization, operations, etc)

3. General conditions of daily life (sporting activity, clothing, time spent in various activities etc)

4. Occupational life (occupation, average working hours, time off work due to sickness, etc)

5. Sociodemographic criteria (age, sex, marital status, insurance coverage, etc)

The target group of nonpurchasers received a questionnaire omitting the area of questioning on . the characterization of venous insufficiency and concentrating solely on items 2 to 5 .

\section{Results}

Since the spectrum of data is very wide, the focus is only on certain characteristics and points of interest. These include the following:

- sociodemographic characteristics

- working hours and impediments

- risk factors

- purchasing structure for phlebotonic medicines

- number of times both target groups visit their physicians

\section{Lifestyle of Purchasers and Nonpurchasers}

In this section, the sociodemographic data and working conditions were studied in selected examples.

The proportion of women in the purchaser group is considerably higher $(80 \%)$ than that of men $(20 \%)$. There is no such difference in the nonpurchaser group, where the potential is balanced (Figure 2).

As the age structure shows (Figure 3), the majority of people in the purchaser group are over fifty years old, with the other three categories accounting for just a quarter of all purchasers. However, this is not the case for the age distribution in the nonpurchaser group. The proportion of over-fifty-year-olds is more than 30\% lower than in the purchaser group, at around $42 \%$. In contrast, the percentages of the other four age groups are higher. 


\section{Figure 2.}

Profile of purchasers and nonpurchasers of phlebotonic medicines in relation to gender.

Figure 3.

Profile of purchasers and nonpurchasers of phlebotonic medicines in relation to age.

in \%

80

0

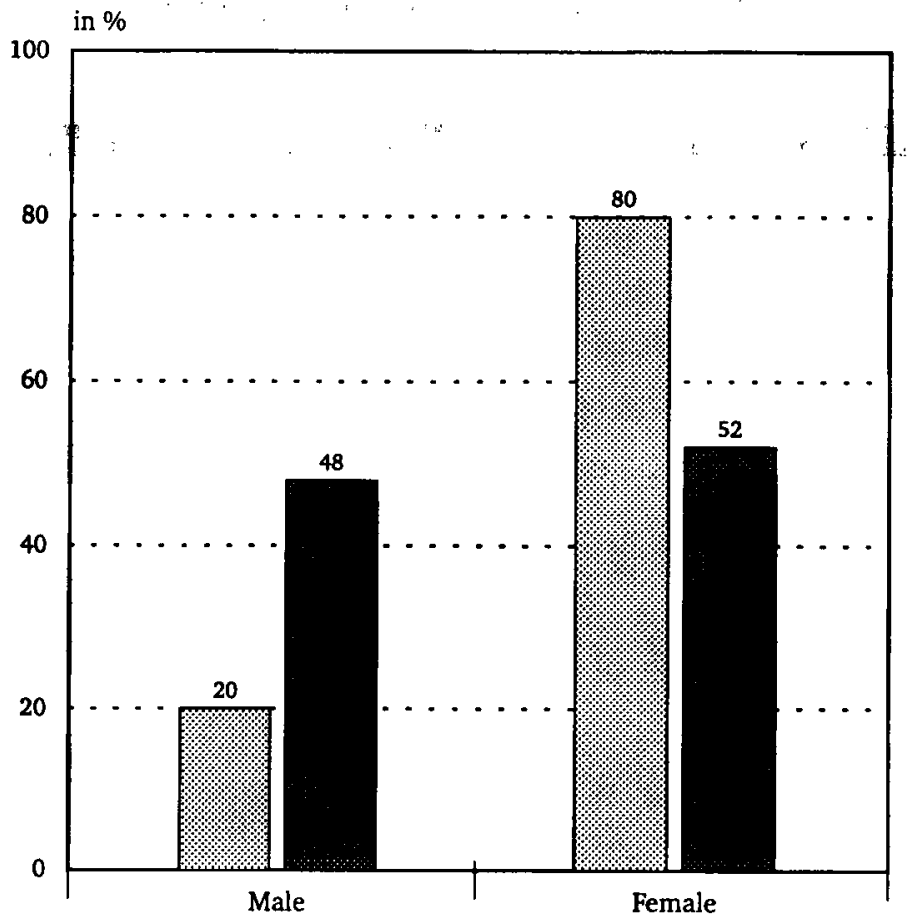

Purchasers

Nonpurchasers
Purchasers: $1,930=100 \%$ Nonpurchasers: $2,291=100 \%$

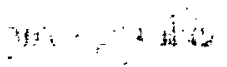

40

0

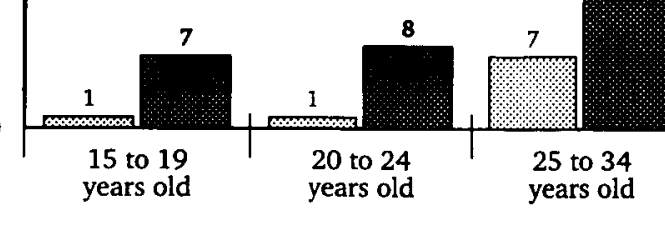

Purchasers

Nonpurchasers

Purchasers: $1,930=100 \%$ Nonpurchasers: $2,291=100 \%$ 
Just over one third of purchasers are retired or coming up to retirement. The second largest group of $30 \%$ are housewives and $29 \%$ give their status as employed. The other $5 \%$ are unemployed, at school, students or "other." In contrast, the profile of the nonpurchaser group shows that more than half the nonpurchasers (56\%) are employed, while the percentage of nonpurchasers in retirement or coming up to retirement $(17 \%)$ and that of housewives are substantially lower than in the purchaser group. Five percent more than in the purchaser group are in the "at school or student" category, $1 \%$ of nonpurchasers are unemployed, and 3\% are classified as "other" (Figure 4).

Purchasers largely fall within the income categories of 1,500 to $2,999 \mathrm{DM} /$ month, whereas nonpurchasers are mainly in the income categories of $3,000 \mathrm{DM} /$ month or more (Figure 5).

Closely linked with monthly income is the level of education (Figure 6). A total of $88 \%$ of purchasers have either a secondary school certificate $(50 \%)$, GCSE $(23 \%)$, or have been to techni- cal college $(15 \%)$; $9 \%$ have A levels or a university certificate. The percentage of the last two categories is around $13 \%$ higher in the nonpurchaser group. Here, $14 \%$ of nonpurchasers went to a grammar school and $8 \%$ to university, but here, the higher percentages are for secondary school (39\%) and GCSE (26\%), too.

As the final point in this section "lifestyle," working conditions are considered with the example of hours worked per week (Figure 7). The significant factor in the purchaser group is the low percentage of employed people - standing at just $29 \%$ - whereas more than half of the nonpurchasers are employed.

\section{Morphology and Therapy}

The complaints of purchasers, which lead to the purchase of medicine, the risk factors, and the consequences of venous insufficiency for those affected are to be considered.
Figure 4.

Professional status of purchasers and nonpurchasers.

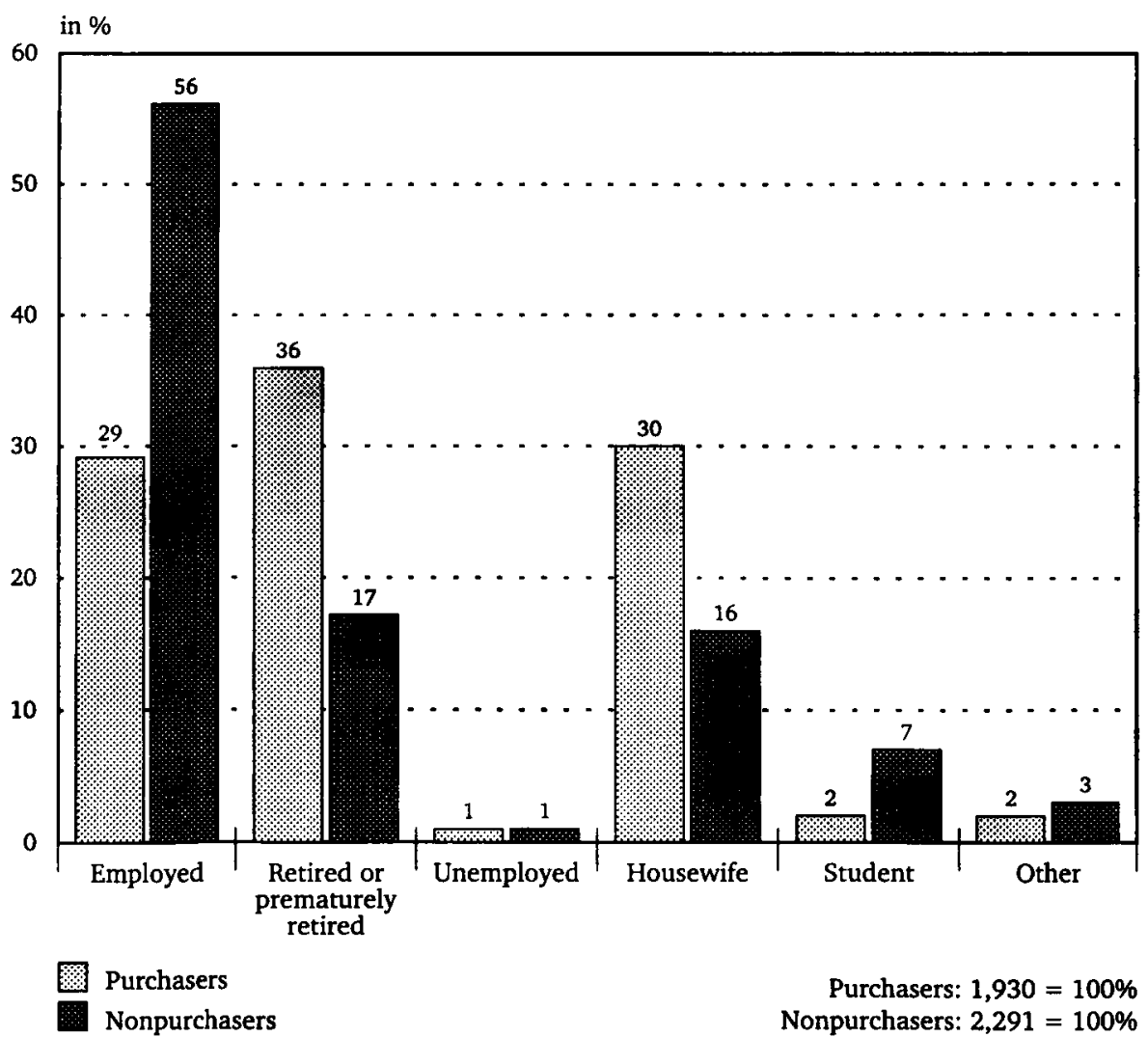


Figure 5.

Monthly income of purchasers and nonpurchasers.

Figure 6.

Level of education of purchasers and nonpurchasers.
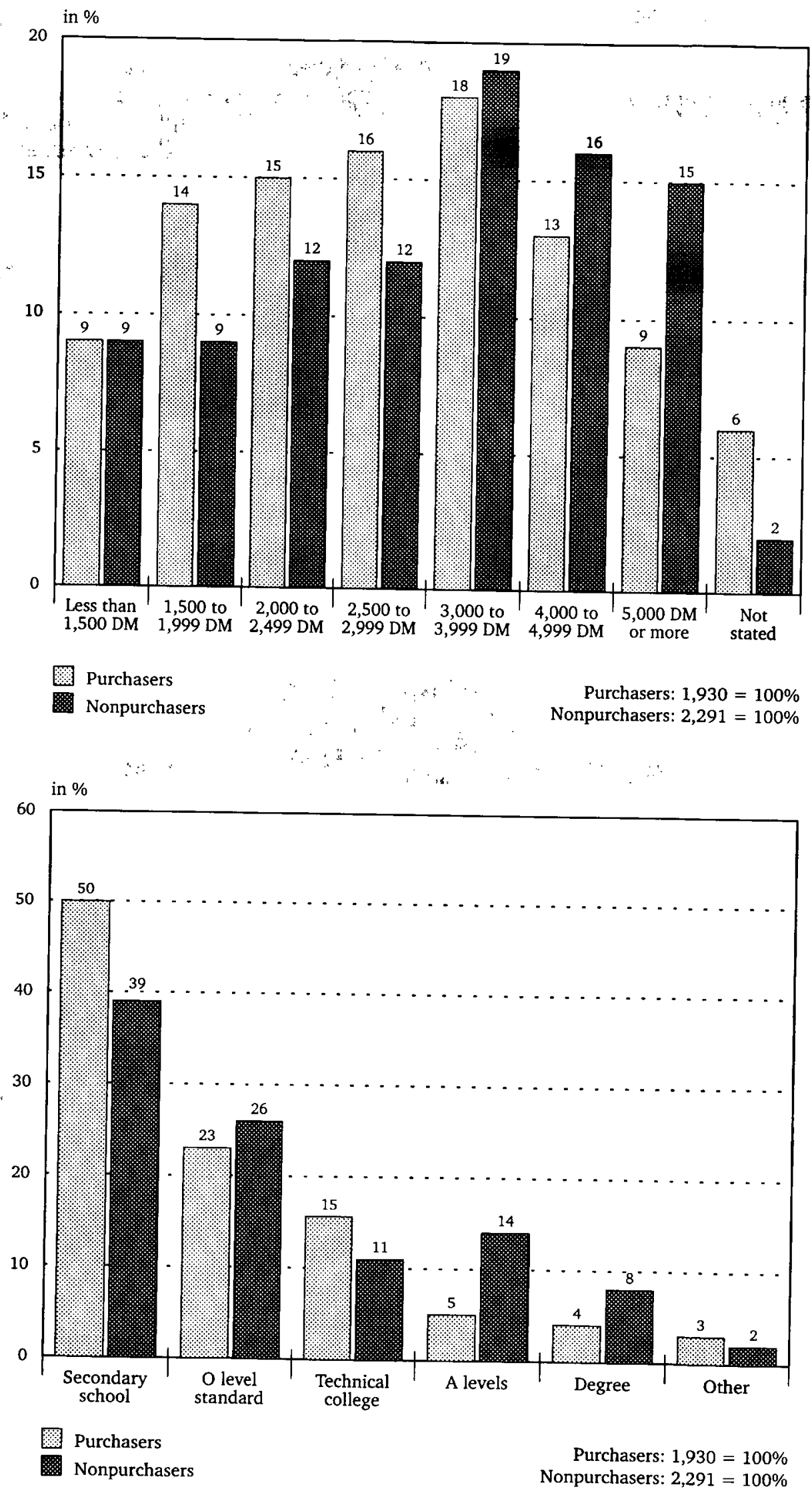
Figure 7.

Weekly working hours of purchasers and nonpurchasers. in $\%$

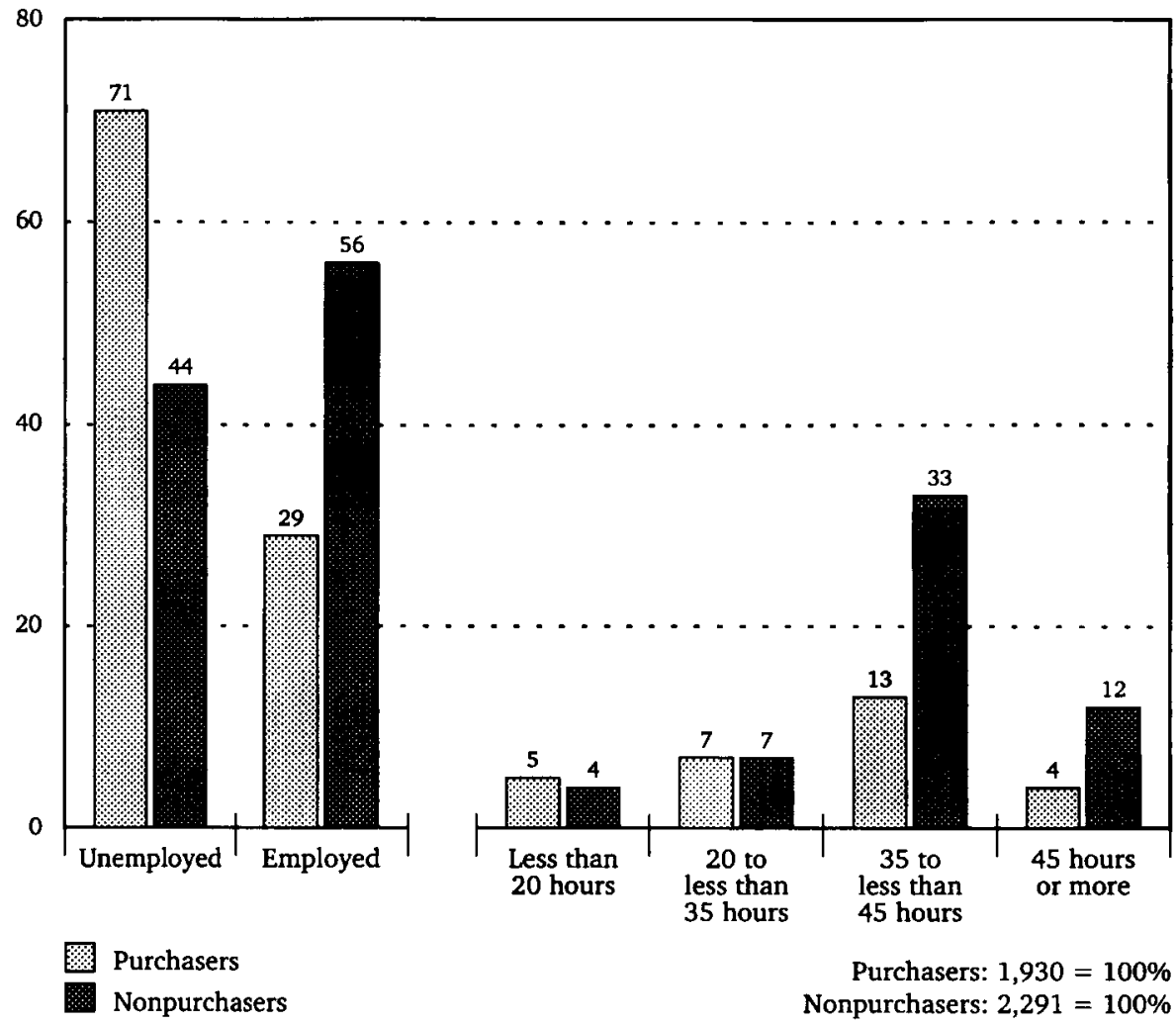

\section{Complaints}

Varicose veins are the most frequent symptoms and prompt $58 \%$ of those affected to buy phlebotonic preparations. The complaint profile is, however, varied. In addition to the varicose veins mentioned, heavy legs with pain, swollen legs, and nighttime cramps are, for $30 \%$ of purchasers, the reason for the use of a medical cream or gel. Complaints tend to occur, not individually, but in combination (Figure 8).

\section{Risk Factors}

Pregnancy. Purchasers of phlebotonic preparations have on average been pregnant more often than nonpurchasers. The number of women questioned in the group of nonpurchasers who have not been pregnant is particularly high. Of 1,187 nonpurchasers, $33 \%$ have never been pregnant in comparison with only $18 \%$ of purchasers. There is no significant difference between the two target groups for the birth of one or two children. The proportion of purchasers is larger as the number of pregnancies increases (3 or more) (Figure 9).

Chronic Diseases. More than half of the purchasers have at least one chronic disease, in many cases high blood pressure and coronary heart diseases. In contrast to the purchasers, the number of nonpurchasers with chronic diseases is substantially lower (Figure 10).

Tobacco Consumption. Tobacco consumption as a predisposing factor can be ruled out. Only 14\% of purchasers smoke, and the majority have either never smoked or given it up (Figure 11).

\section{Consequences of Venous Insufficiency}

Although the majority (57\%) of those afflicted perceive their problem to be very or fairly unpleasant, leg complaints negatively affect $45 \%$ of purchasers in their free time or family life. The disease, furthermore, has no effect on the number of annual days of sickness, for the majority of purchasers have no days off for illness in the year (Figure 12). 
Figure 8.

Complaints leading to the purchase of medicines.

\section{Figure 9.}

Number of pregnancies in purchasers and nonpurchasers.
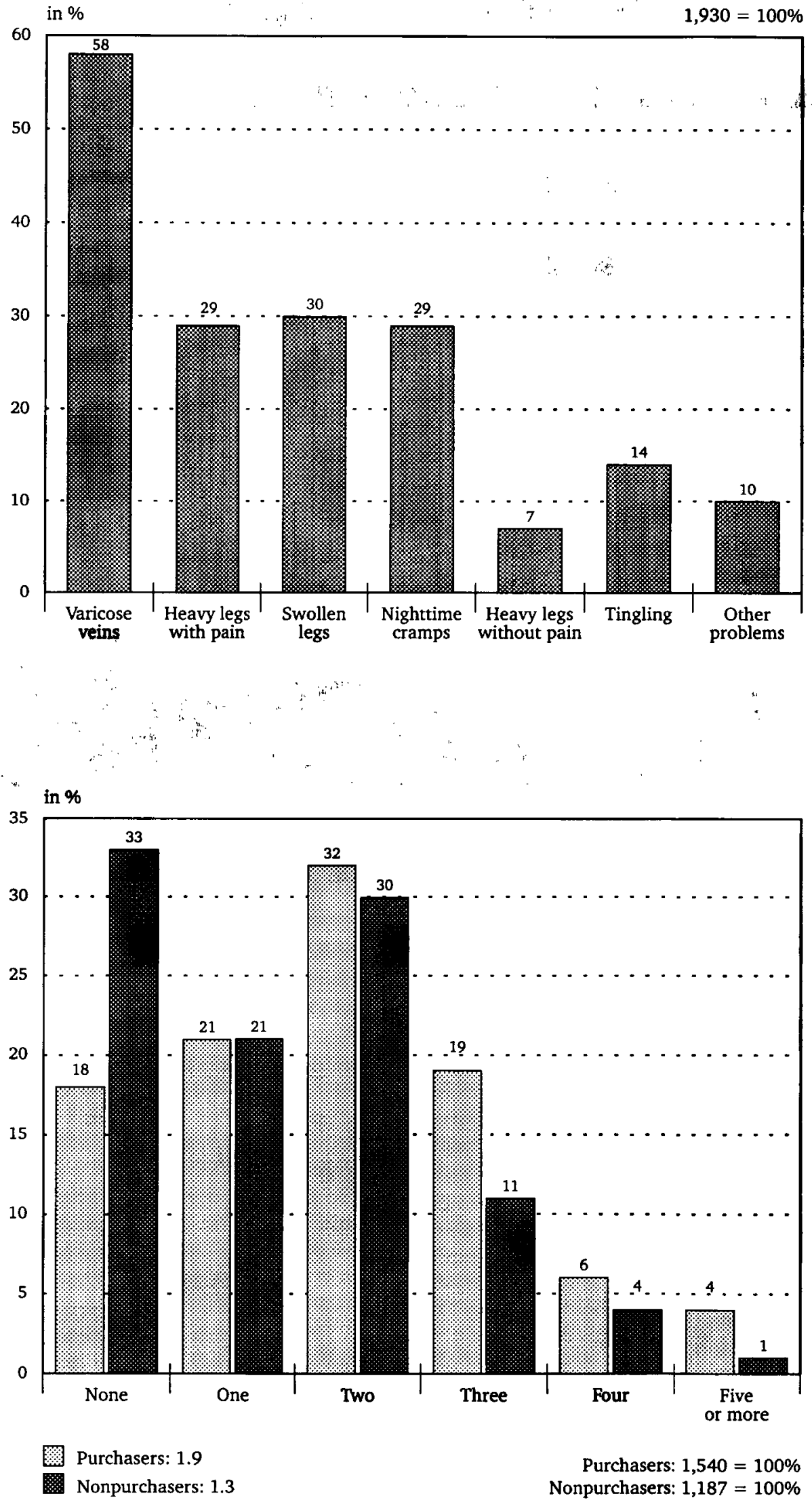
Figure 10.

The presence of chronic disease in purchasers and nonpurchasers.
Figure 11.

Tobacco consumption by purchasers. in $\%$

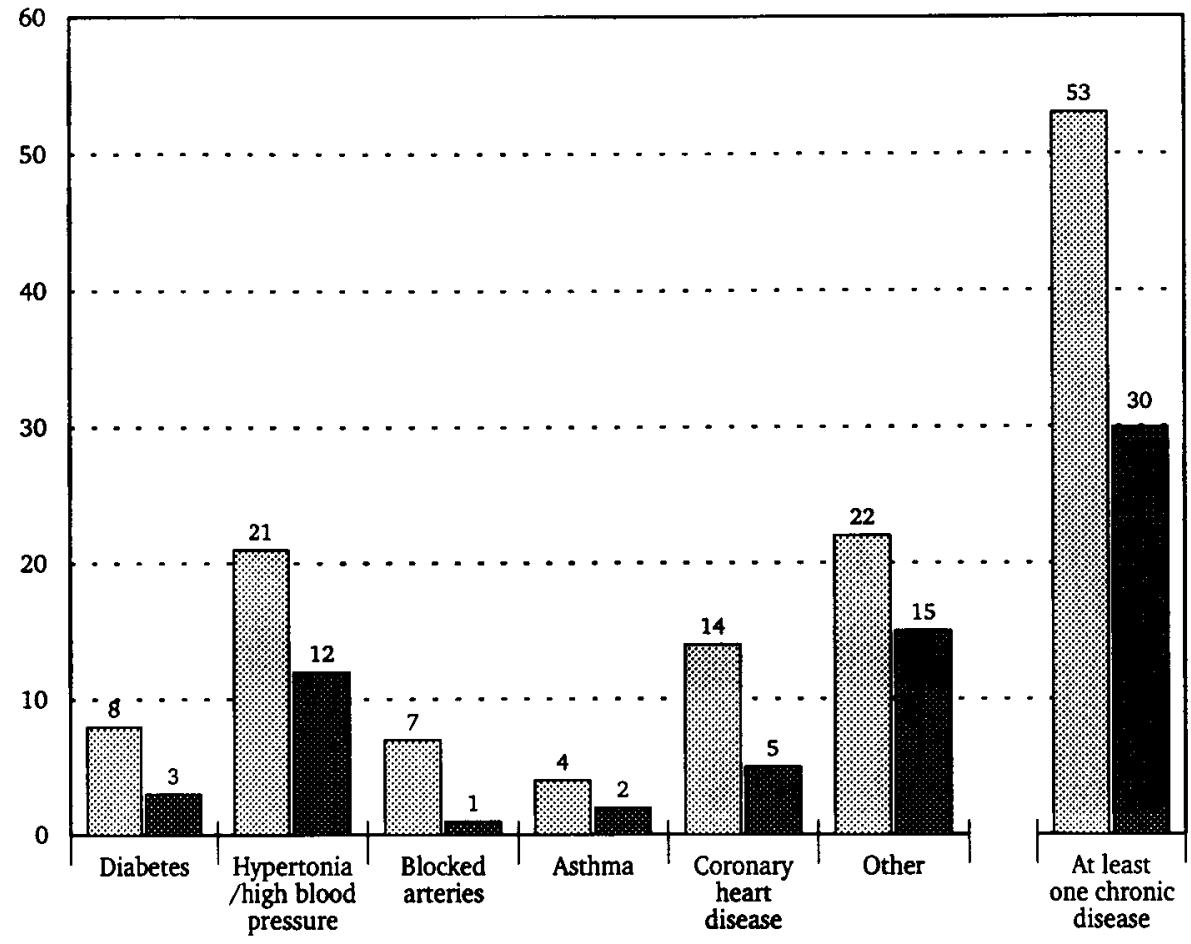

Purchasers

Nonpurchasers Nonpurchasers: $2,291=100 \%$

in $\%$

Basis: purchasers $1,930=100 \%$

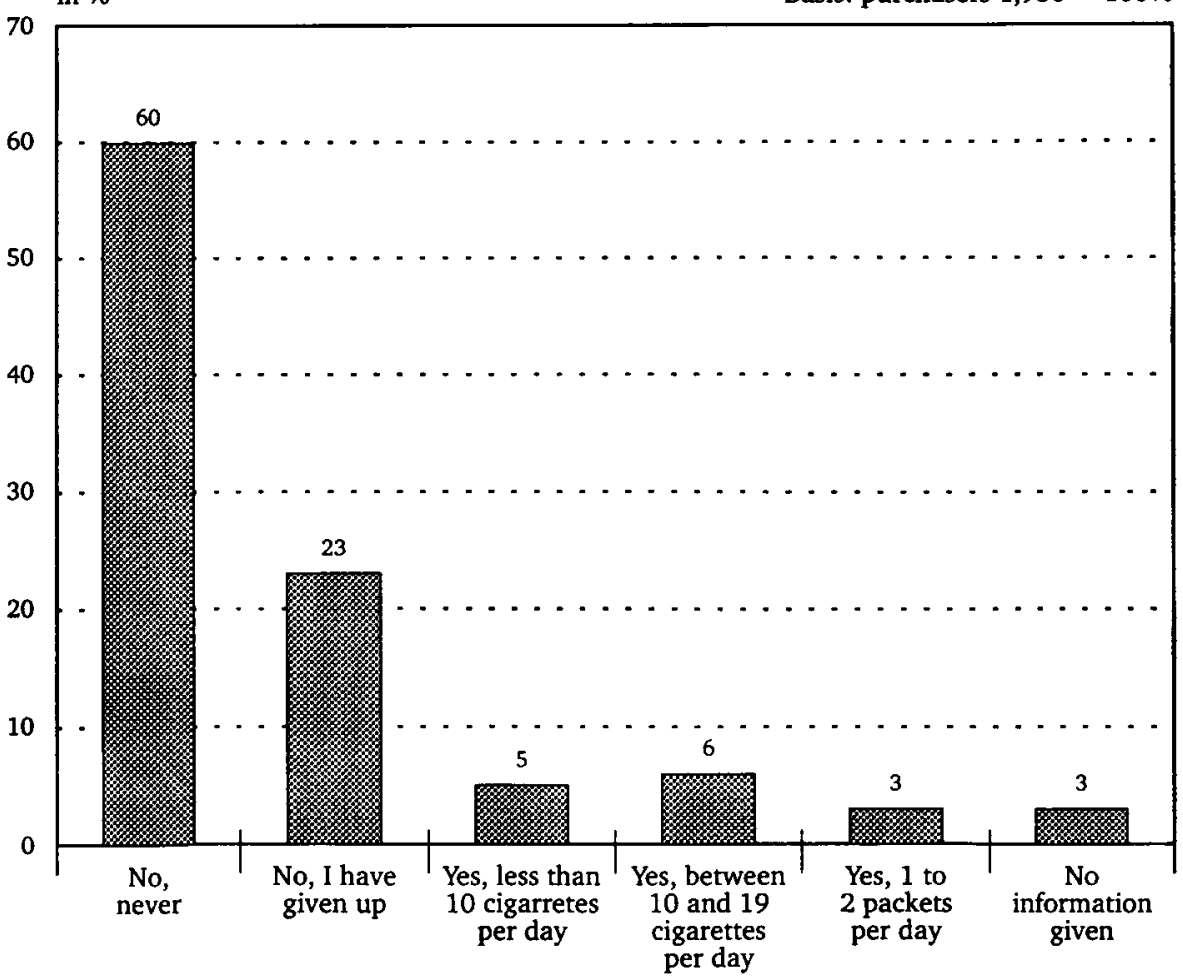


Figure 12.

Number of days on sick leave per year.

\section{Treatment Options}

The treatment options for venous insufficiency were mentioned briefly in the introduction. In this study, however, only medicinal therapy was considered. Figures 13 and 14 show the purchase of medicines with and without prescription. There were about 16 million prescriptions in Germany in 1993. The cost of this type of treatment reached 520 million marks.

The purchasers visited their physicians on average 3.7 times because of their leg problems. The noticeable factor here is that considerably more workers and retired people go to the physician. Another striking feature is that more than $40 \%$ of managing directors, businessmen, and tradesmen do not see a physician at all (Figure 15).

\section{Interpretation of Results and Conclusion}

This detailed description indicates that it is overwhelmingly people over fifty and women who
Basis: all employed $564=100 \%$

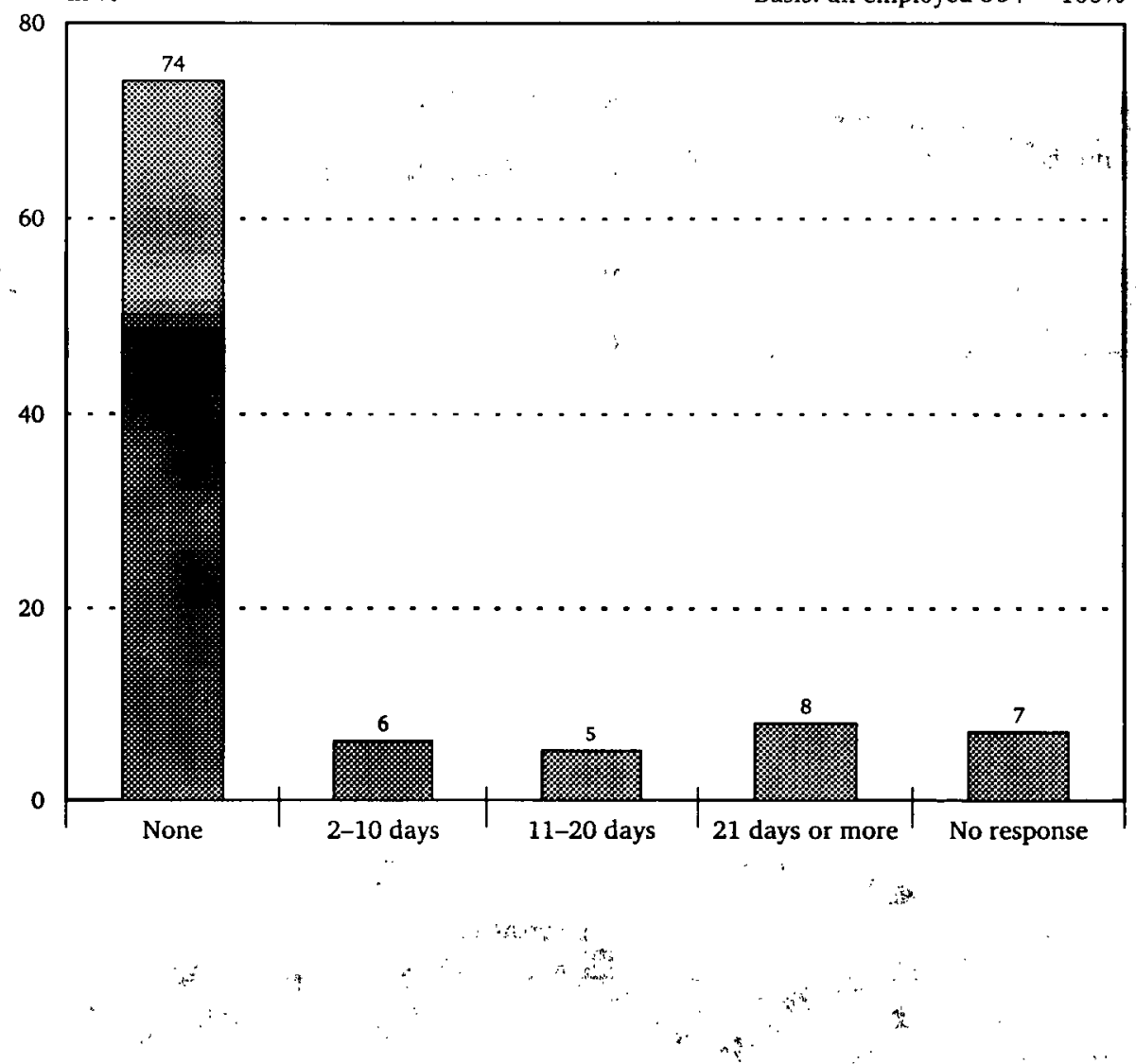

suffer from this disease. Those affected are mainly retired or approaching retirement or are housewives. The purchasers of phlebotonic medicines are in the lower and middle income classes, which is directly related to level of education.

Those affected purchase vascular drugs because the disease is associated with a high level of pain. This is very clear from the complaint profile described, consisting of varicose veins, heavy legs with pain, swollen legs, and cramps at night.

The risk factors explained lead to the conclusion that frequent pregnancy does not predispose to the disease but can have the effect of exacerbating it. Another noticeable factor is that more than half of the purchasers already suffer another chronic disease.

On average, purchasers see their physicians 3.7 times because of their afflictions. The most frequent consultations are due to the need for a new prescription, for three quarters of purchasers do not have any annual days off sick.

Whether consumers would purchase so many medicines if they were not obtainable on prescription is a particularly pertinent question. The 
Figure 13. Purchase of medicines in the last twelve months with prescription.

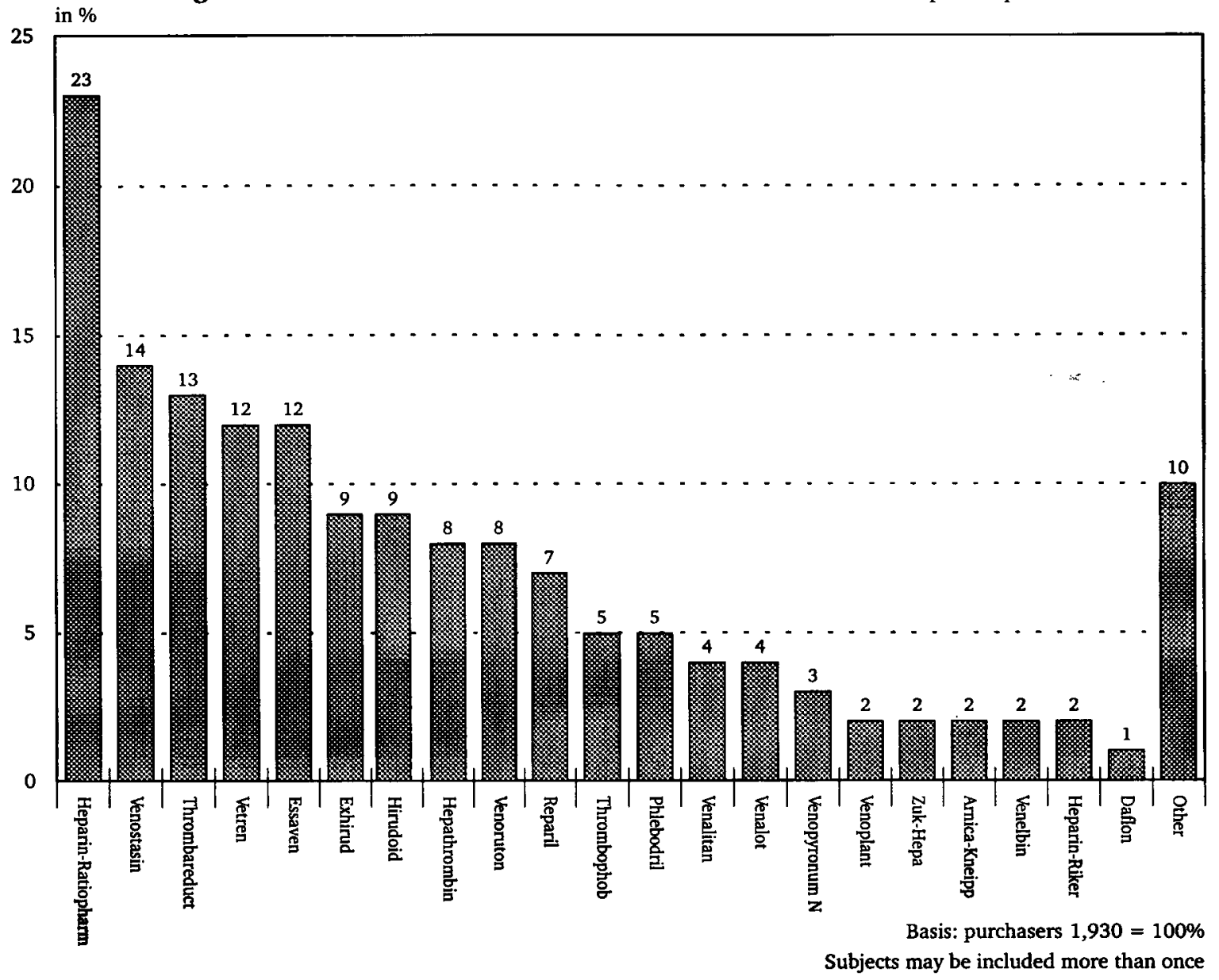

Figure 14. Purchase of medicines in the last twelve months without prescription.

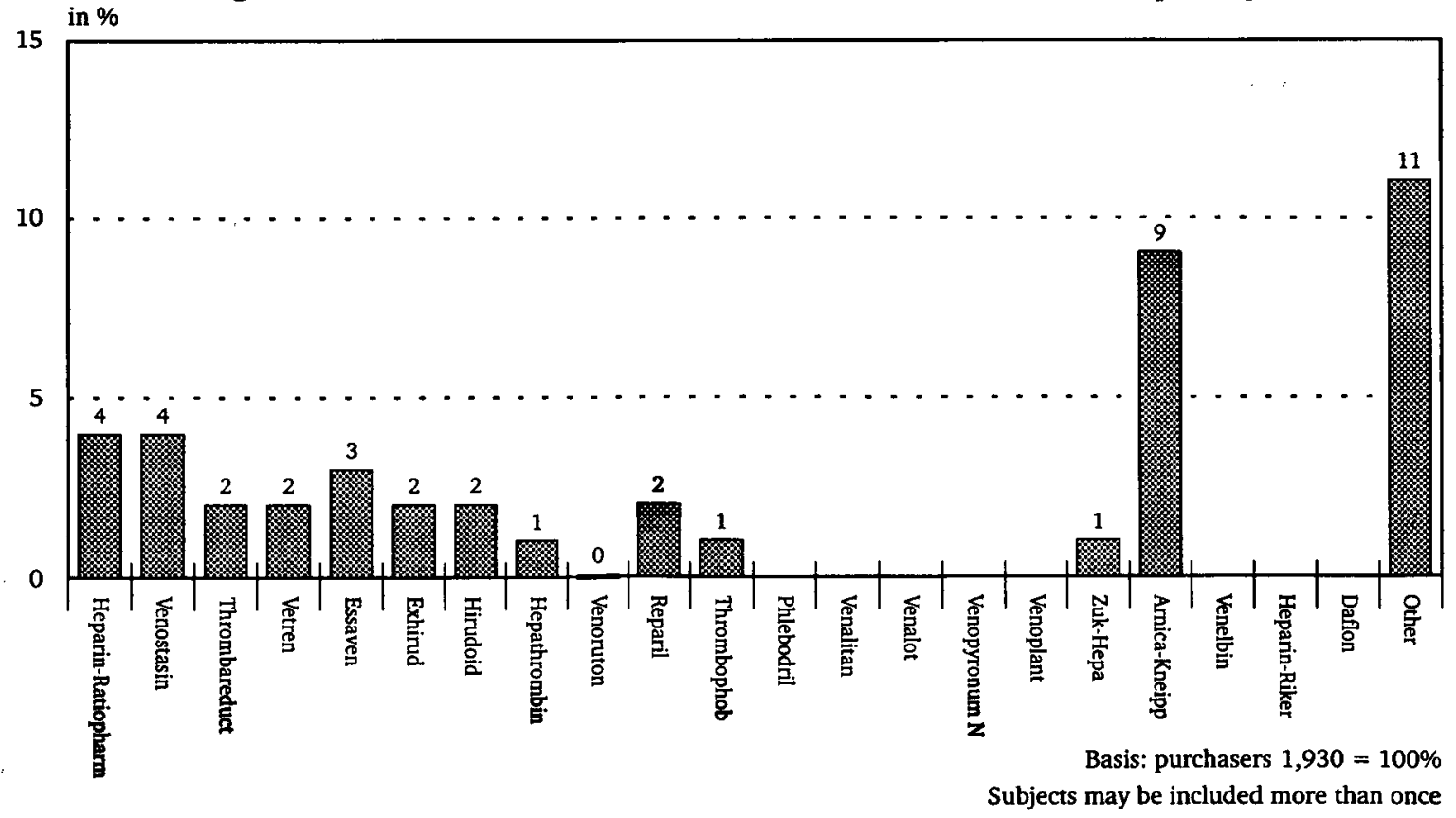


Figure 15. Number of visits to a physician for leg problems.

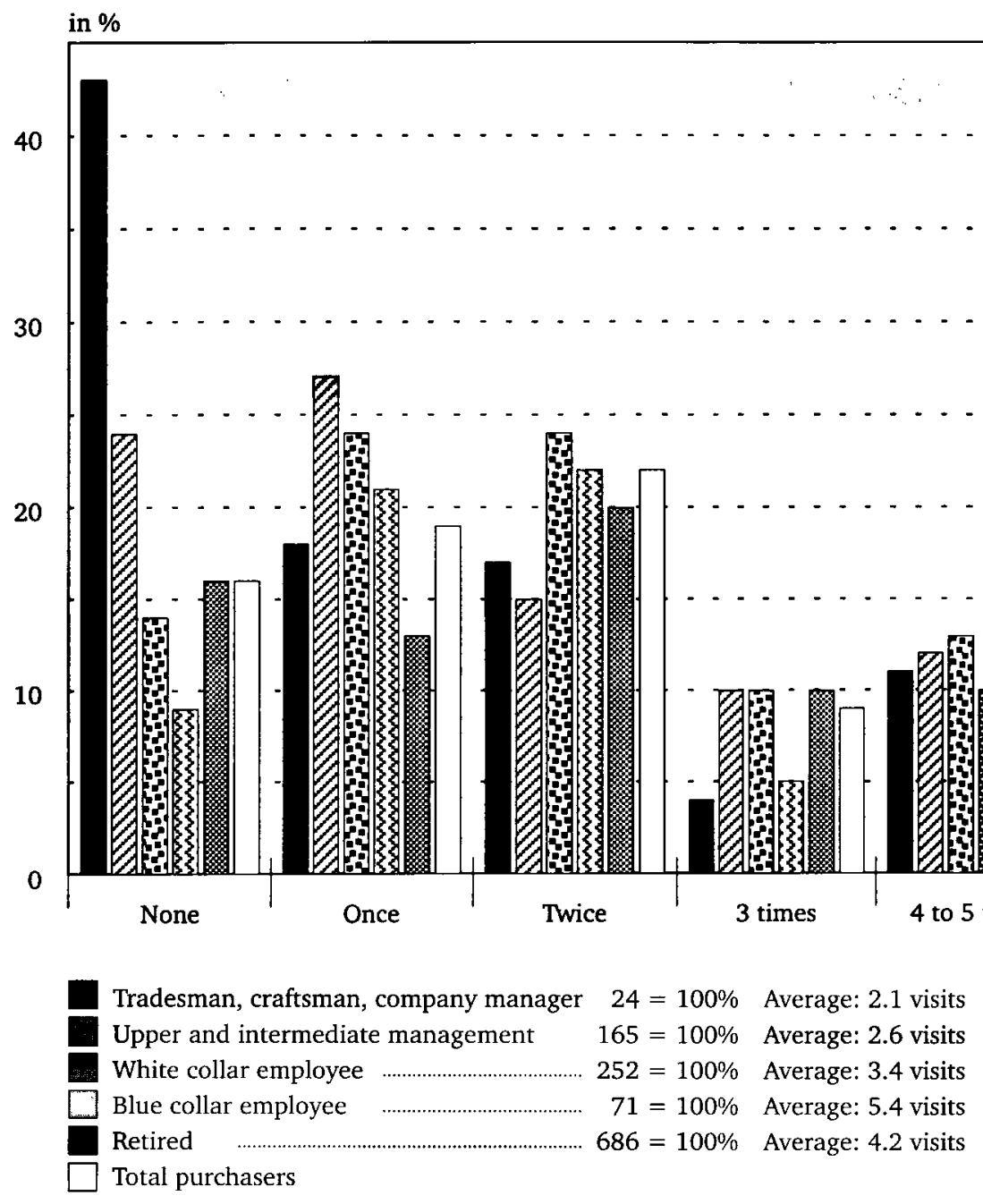

Basis: purchasers $1,930=100 \%$ Average: 3.7 visits

result is interesting, for $5 \%$ of purchasers would do without the preparations and $22 \%$ would reduce their consumption. Purchasers with children and a lower monthly income are particularly those who would do without or limit their consumption. Naturally, this raises the question of whether there is a two-class medical system, for those on higher incomes could buy the medicines, creams, or gels as they want, and indeed will do this even if they are not reimbursed by their health insurance fund. Doubts about therapeutic effectiveness provide, however, arguments for banning prescriptions of vascular drugs.
On January 1, 1993, the new Health Care Reform Act (in Germany called Gesundheitsstrukturgesetz) came into effect. In 1993 a global budget was introduced for medicines: that means for the year 1993 the budget for drug expenditures was fixed on the basis of the expenditure for drugs in 1991 (almost 224 billion DM). This budget is the limit for the prescriptions of all officebased physicians. If this budget is exceeded, physicians are required to pay the excess amount up to 280 million DM. In January 1993, the level of prescriptions by office-based physicians, dropped by more than $30 \%$ compared with the 
average of 1992. Compared with December 1992 the reduction was nearly $50 \%$. Under these circumstances it is not surprising that the prescriptions of phlebotonic preparations decreased by $26.9 \%$ and sales dropped by $31.1 \%$ in 1993 compared with 1992.

Andrea Uber, MBA

Institute for Insurance Economics

University of Hanover

Königsworther Platz 1

30167 Hanover

Germany

1. Hitzenberger G: Die therapeutische Wirksamkeit des Roßkastaniensamenextraktes. Medizinische Wochenschrift 139:385-389, 1989.

2. Fricke U: Venenmittel. In: ArzneiverordnungsReport, ed. by Schwabe U, Paffrath D. Stuttgart: Jena, 1993, pp 397-406.
3. Le Pen C, Levy E: Socio-économie de la maladie veineuse: Les enseignements d'une enquête sur les consommateurs de médicaments phlébotoniques en France. Paper der Laboratoire d'Economie et de Gestion des Organisations de Santé. Université ParisDauphine (result of study), 1991. 